\title{
Quick parathyroid hormone assays: a comprehensive review of their utility in clinical practice
}

\author{
Michael S. Shawky ${ }^{1,2}$ \\ ${ }^{1}$ Department of Head and Neck and Endocrine Surgery, Faculty of Medicine, University of Alexandria, Egypt; ${ }^{2}$ Department \\ of Surgery, University College Hospital, London, UK
}

\begin{abstract}
Continuous development of quick parathyroid hormone assays has resulted in a corresponding expansion of their applications in the practical landscape. In-theatre measurement of the parathyroid hormone has long been recognized as a valuable adjunct in parathyroid surgery, with other applications being incorporated in thyroid surgery and out-of-theatre uses. Such widespread utilization of these assays has also brought the concept of point-of-care testing to the endocrine surgical patient. We have herein summarized the established and potential applications of these assays, emphasizing their importance in the point-of-care setting, highlighting the proper selection of the assay type for intraoperative hormone monitoring and spotlighting those applications which should be validated for use in the clinical setting and those which need to be investigated further.
\end{abstract}

Key words: Intraoperative parathyroid monitoring, Parathyroid hormone assay, Point-of-care testing, Post-thyroidectomy hypocalcemia

\section{INTRODUCTION}

Advances in clinical biochemistry have resulted in the development of improved assays for hormone measuring. Among the most prominent of these are the quick parathyroid hormone (qPTH) assays, since they have been found to help address a number of challenging issues in parathyroid, and to a lesser extent in thyroid, surgery. A multitude of platforms have therefore been developed to better address these

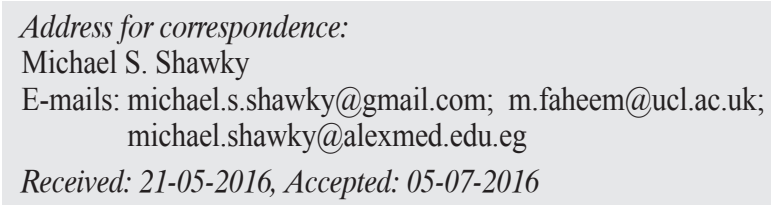

issues. These platforms share a similar three-step analytical principle: 1) capturing the PTH molecule in a specific sample volume through recognizing a specific amino acid sequence within the PTH peptide by specific antibodies, 2) detection of the antibodycaptured PTH molecule using signal-labeled specific antibodies and 3) reading the amount of signal with subsequent quantification of PTH. The antibodies used are usually polyclonal goat antibodies and the signal is of the Chemiluminescence type. Some differences, however, exist among these platforms regarding the solid phase and the incubating conditions, with consequent variations in the volume of sample required, time to result and the measurement range. ${ }^{1}$ This notable development in the laboratory landscape 
has been reflected in a corresponding expansion of clinical applications in the practical landscape. Quick measurement of PTH in blood samples from on-table patients has attracted much attention in the context of intraoperative parathyroid monitoring (IPM). However, qPTH assays have also been used for in-theatre measurement of PTH in suspected tissue or fluids as well as for out-of-theatre purposes. In addition, these assays have improved the quality of care by enabling the performance of the test within a short turnaround time and near to the site of patient care, two points which basically define the concept of point-of-care testing (PoCT). ${ }^{2}$ Given such rapid expansion of these assays' applications, this is an opportune moment to review the relevant current knowledge. Like any technology, their use is not however free from drawbacks, such as measurement pitfalls and the extra cost involved, which considerations are reviewed elsewhere. Our focus in this article is to summarize the established applications and discuss the emerging ones, emphasize their role in provision of bedside patient care in endocrine surgery and highlight the proper selection of the assay type for intraoperative hormone monitoring with a view to identifying those applications which need to be investigated further and those which should be considered for validation in the clinical setting.

\section{METHODS}

Our first step in accomplishing the goal we had set was to perform a structured search of Embase and Medline electronic databases using Ovid interface. Our strategy consisted in searching in all fields (af), using keywords extracted from the relevant $\mathrm{MeSH}$ headings, which were then combined using the Boolean operators, employing the following search terms: (intraoperative AND parathyroid), (point-of-care AND parathyroid), and (quick assay AND parathyroid). Limitations applied were: 1) English literature, 2) human studies and 3) publication year (2003 - current). Full text manuscripts of relevant records were assessed for eligibility. Eligible articles were those clearly mentioning the use of quick PTH assays for PTH measurement. A few relevant articles were also added from other sources, mainly from the selected manuscript bibliographies, so that a total of 106 publications were used to construct this narrative review.

\section{IN-THEATRE USE OF QPTH ASSAYS IN PARATHYROID SURGERY}

The utilization of qPTH assays has brought many benefits to parathyroid surgery, primarily through intraoperatively monitoring the hormone level in blood samples drawn from the patients and, to a lesser extent, through measuring the hormone level in suspected tissues.

\section{Intraoperative parathyroid hormone measurement in blood samples}

Recording the decline of intraoperative PTH (IOPTH) in serial samples taken at defined time points during surgery (i.e. IOPTH monitoring or IPM) has gained much interest, with extensive discussions and multiple protocols investigated in the literature. Some authors, however, have reported that other benefits can be derived from a single IOPTH measurement at the start of surgery and from observing IOPTH kinetics.

\section{The role of hormone monitoring in assuring the adequacy of parathyroid surgery}

Physiological and pathobiological basis

Achieving a satisfactory post-excision reduction of IOPTH at a defined time point, in comparison to a baseline level, is a reliable criterion that the hyperfunctioning parathyroid tissue has been adequately removed and surgery can be safely concluded, thereby predicting subsequent surgical success..$^{3-5}$ Three physiological facts have formed the scientific background to such a concept: 1) the PTH molecule is solely released from the secretory granules of the chief cells within the parathyroid glands, ${ }^{6} 2$ ) normally functioning parathyroid glands are suppressed by excess PTH released by the hyperfunctioning gland(s) ${ }^{1}$ and 3 ) the half-life of PTH has been calculated by various assays to be less than 5 minutes. ${ }^{7}$ While this concept has been approved and used by many surgeons to assure the adequacy of surgery in primary hyperparathyroidism (PHPT), its use has nevertheless not found a similar place in renal HPT.

Several protocols have been proposed for deciding the adequacy of surgery in HPT, e.g. Miami, Halle, Vienna and Rome. ${ }^{8}$ Variable performance has been achieved by these protocols owing to their controversial parameters, e.g. required PTH drop, baseline 
PTH level and timing of decision. ${ }^{9}$ Despite the debated parameters, IPM's ability to achieve early prediction of surgical adequacy has supported the implementation of minimal access surgery (MAS) in HPT surgery and has improved surgical success rates.

\section{Implementing minimal access surgery}

For PHPT patients with localizing preoperative scans, IPM has enabled surgery to be conducted through unilateral exploration, ${ }^{10}$ and even obviating the need to visualize the ipsilateral possibly normal gland. ${ }^{11}$ This subsequently has standardized the concept of MAS for the surgical management of PHPT (minimally invasive parathyroidectomy, MIP) with the multiple techniques that already exist or are evolving (focused, endoscopic, video assisted, radioguided ${ }^{12}$ or roboticassisted $^{13-16}$ ). Additionally, operating through MAS has allowed PHPT surgery to be occasionally carried out under local anesthesia ${ }^{17}$ and even be practiced as day-care surgery. ${ }^{18}$ In addition to gaining the expected advantages of MAS (e.g. minimal incision, minimal dissections and short hospital stays), excellent cure rates have been achieved, ${ }^{17}$ with the risk of persistent or recurrent disease comparable to traditional bilateral neck exploration (BNE) ${ }^{19,20}$ Furthermore, cases with prior contraindications to MIP, including parathyroid cancer, prior neck surgery (persistent or recurrent HPT) and high risk of multiglandular disease (MGD) (i.e. risk of parathyroid hyperplasia in patients having familial HPT or a history of prior neck radiation), ${ }^{21}$ can occasionally be concluded through various MAS techniques, aided by IPM. ${ }^{22-26}$ Likewise, approaching an ectopic mediastinal parathyroid through videoassisted thoracoscopic surgery (VATS) has also been facilitated through IPM. ${ }^{27,28}$ On the other hand, BNE should prudently be prompted if IOPTH does not show satisfactory reduction. Indeed, albeit classic BNE is still resorted to as initial surgery in selected PHP cases or as conversion after failed MIP, its appeal and indications have obviously progressively decreased in the era of IPM-guided MIP. ${ }^{29}$

Similarly to PHPT, surgery has been accepted as the standard of care for management of tertiary HPT (THPT). By contrast, however, the management of secondary HPT (SHPT) is predominantly medical, with surgery required only in severe cases as indicated by calciphylaxis or PTH level higher than
$800 \mathrm{pg} / \mathrm{ml} .{ }^{30}$ While IPM-guided MAS has become a routine practice in managing PHPT patients, it has not yet found a similar place in SHPT and THPT, i.e. renal HPT surgery for two main reasons. Firstly, in patients with renal HPT, the four glands are almost always hyperplastic ${ }^{30}$ this consequently emphasizes the importance of visually inspecting the four glands at surgery, necessitating therefore adequate exposure. In support of the latter, a significantly lower failure rate has been associated with adequate in comparison to inadequate surgery (defined as more vs less than $3 \frac{1}{2}$ gland resection). ${ }^{31}$ Secondly, some studies have demonstrated lack of correlation between percent IOPTH decline and operation outcome or postoperative PTH in renal HPT patients, findings which question the efficiency of IPM in assuring the adequacy of renal HPT surgery. ${ }^{32,33}$ However, in addressing these two issues, it has been demonstrated that both neck sides could possibly be explored through the central access provided by video-assisted neck surgery (VANS) ${ }^{34}$ In addition, IPM has been demonstrated in other studies to efficiently predict the success of parathyroidectomy for renal HPT. Hence, reasonable evidence exists to support investigating whether surgery for renal HPT could be efficiently concluded through IPM-guided MAS. Indeed, when guided by IPM, minimally invasive video-assisted parathyroidectomy (MIVAP) for SHPT has been successfully completed in $92 \%$ of cases, as reported by Alesina et $\mathrm{al}^{35}$ in their initial experience. In contrast, conversion to traditional BNE has been reported in $30 \%$ of SHPT patients initially undergoing non-IPM-guided MIVAP. ${ }^{36}$

\section{Reduction of operative failures}

The term operative failure, equivalent to persistent HPT, is defined as occurrence of a HPT biochemical profile within six months of surgery and, broadly speaking, can be attributed to technical, structural or pathobiological issues.

Firstly, from the technical point of view, surgeon experience has, on the one hand, been recognized as being pivotal in parathyroid surgery; hence, an inexperienced surgeon would be expected to have a higher failure rate. In their retrospective study, Nawrot et $\mathrm{al}^{37}$ reported having missed hyperfunctioning parathyroid tissue in $55.5 \%$ of patients undergoing reoperative surgery which, having been detected in a 
eutopic position, was likely due to lack of adequate surgical expertise. Monitoring PTH intraoperatively would provide a simple biochemistry based tool to assess the adequacy of resection, either assuring the surgeon that surgery can be concluded or prompting him to take further action, e.g. convert to BNE (if initially performing MIP), or to carry out further exploration (if already performing BNE) or to seek the assistance of a senior surgeon. On the other hand, surgical decision-making, being influenced by non$100 \%$ accurate preoperative scans, could occasionally be incorrect. Such a decision could be changed intraoperatively according to whether IOPTH achieved satisfactory reduction. ${ }^{38}$

Structural variations of the parathyroids, on a second perspective, are not uncommon, with ectopic glands being reported in $16 \%$ of HPT cases. ${ }^{39} \mathrm{Su}-$ pernumerary parathyroids are also reported to exist in up to $13 \%$ of individuals. ${ }^{40}$ Such aberrant glands could be missed and, if pathological, persistent PHPT would result. ${ }^{41,42}$ In addition, a missed aberrant gland in renal patients may undergo hyperplasia as a result of uremic stimulation, thereby putting the patient at risk of recurrent SHPT and ultimately necessitating reoperation. ${ }^{43}$ Indeed, missed ectopic adenomas have been reported in 53\% of PHPT patients undergoing reoperation. ${ }^{44}$ In their study of PHPT patients who underwent reoperative surgery, Mariette et $\mathrm{al}^{45}$ have reported supernumerary glands in 15 out of 38 cases. In their retrospective analysis of 165 reoperated SHPT patients, Okada et al ${ }^{43}$ have reported "supernumerary" glands in $68 \%$ of patients, whereas $48 \%$ of glands excised in reoperative surgery were found in ectopic locations. Employing IPM has been reported to be useful in predicting complete removal of the hyperfunctioning parathyroid tissue, including suspected aberrant tissue. ${ }^{46,47}$

Thirdly, pathobiologically speaking, MGD, including hyperplasia and double adenomas, and parathyroid cancer (PC) account for $15 \%$ and $1 \%$ of PHPT, respectively; nevertheless, they have been reported in $28.4 \%$ to $60 \%$ and $2 \%$ to $3.4 \%$, respectively, of reoperative PHPT patients. ${ }^{45}$ Persistence/recurrence rates of PHPT have been reported to be incrementally higher following surgery for single adenoma, hyperplasia and double adenoma. ${ }^{48}$ The latter issue would also be addressed through IPM because of its ability to predict MGD not only through showing "failure to decline" but also through demonstrating a "slow rate of decline". ${ }^{49}$ In a study by Sugg et al ${ }^{50}$ combining ultrasound and MIBI, scans predicted MGD in only $30 \%$ of cases, while IOPTH alone was reported to predict it in $83 \%$ of cases. In their study of 260 PHPT patients, Barczynski et al ${ }^{8}$ attributed a significant value of $3.1 \%$ in their overall success rate $(99.6 \%)$ to correctly identifying eight patients with MGD through IPM, despite being incorrectly stratified as solitary adenoma through concordant preoperative scans. In an analysis of PC case series, Soloranzo et $\mathrm{al}^{51}$ reported $87 \%$ PPV of IPM in eight cases who underwent initial surgery; the test was, however, less predictive in reoperative cases. A cure rate of $100 \%$ has subsequently been reported following IPM-guided en-bloc resection in four PC cases, thus supporting its use in such instances. ${ }^{52}$

In terms of addressing such potential causes of parathyroid surgery failures, IPM has been found in many studies to improve the cure rates of PHPT (Table 1).

Similarly, the role of IPM in improving surgical outcomes of renal HPT has been clearly demonstrated by Gasparri et $\mathrm{al}^{60}$ in a retrospective data analysis which captured a reduction of persistence and recurrence rates from $6.2 \%$ and $11 \%$ to $4.9 \%$ and $4.9 \%$, respectively, for SHPT and from $4.7 \%$ and $2.3 \%$ to 2.1 and 0 , respectively, for THPT cases on employing IPM.

\section{Selection of the assay type}

According to the analytical characters, two main types of PTH assays have been recognized: intact and whole PTH assays. The intact PTH assay, also known as second generation assay, reacts not only with bioactive 1-84 PTH fragment but also with non-active large carboxyl terminal PTH fragments, mainly 7-84 fragments. The whole PTH or third generation assay, on the other hand, exclusively reacts with the whole PTH molecule (1-84 fragment). ${ }^{61}$ In comparison to the bioactive fragments, the non-1-84 fragments were reported to have a longer half-life. ${ }^{62}$ Given the fact that the latter fragments are known to accumulate in renal failure patients, ${ }^{63}$ false results would be likely if second generation assays were used for IPM in such patients. A Bio-Intact PTH (1-84 fragments) measuring assay has, however, been reported to be more 
Table 1. Role of IPM in improving surgical cure rates of PHPT

\begin{tabular}{|c|c|c|c|c|c|c|}
\hline \multirow[t]{2}{*}{ Year } & \multirow[t]{2}{*}{ Author } & \multirow[t]{2}{*}{ Type of study } & \multicolumn{2}{|c|}{ With IPM } & \multicolumn{2}{|c|}{ Without IPM } \\
\hline & & & No & Cure rate & No & Cure rate \\
\hline 1999 & Irvin et $a^{53}$ & $\begin{array}{l}\text { Retrospective analysis of outcomes of reoperative } \\
\text { parathyroidectomy with vs without IPM }\end{array}$ & 33 & $94 \%$ & 17 & $76 \%$ \\
\hline 2001 & Agarwal et al ${ }^{54}$ & $\begin{array}{l}\text { Prospective comparative study of MIP with vs } \\
\text { without IPM }\end{array}$ & $\begin{array}{c}\text { Theoretical } \\
\text { model }\end{array}$ & $98.9 \%$ & 88 & $96.6 \%$ \\
\hline 2004 & Udelsman et al ${ }^{17}$ & Retrospective analysis of outcomes of MIP vs BNE & 255 & $99 \%$ & 401 & $97 \%$ \\
\hline 2004 & Irvin et $\mathrm{a}^{55}$ & Retrospective analysis of outcomes of MIP vs BNE & 421 & $97 \%$ & 340 & $94 \%$ \\
\hline 2005 & Chen et $a^{56}$ & $\begin{array}{c}\text { Retrospective analysis of outcomes of MIP with vs } \\
\text { without IPM }\end{array}$ & 188 & $100 \%$ & 157 & $90 \%$ \\
\hline 2007 & Barczynski et al ${ }^{57}$ & $\begin{array}{c}\text { Prospective comparative study of MIP with IPM vs } \\
\text { UNE without IPM }\end{array}$ & 115 & $99.1 \%$ & 62 & $91.1 \%$ \\
\hline 2010 & Sugino et $\mathrm{al}^{58}$ & $\begin{array}{c}\text { Retrospective analysis of outcomes of MIP with vs } \\
\text { without IPM }\end{array}$ & 80 & $97.5 \%$ & 87 & $93.1 \%$ \\
\hline 2015 & Kim et $\mathrm{al}^{59}$ & $\begin{array}{c}\text { Retrospective analysis of outcomes of MIP with vs } \\
\text { without IPM }\end{array}$ & 14 & $100 \%$ & 39 & $94.9 \%$ \\
\hline
\end{tabular}

IPM: Intraoperative Parathyroid Monitoring; MIP: Minimally Invasive Parathyroidecomy; BNE: Bilateral Neck Exploration; UNE: Unilateral Neck Exploration.

accurate in intraoperatively differentiating sufficient from insufficient parathyroidectomy and subsequently in predicting surgical outcome, compared to conventional second generation assay; ${ }^{64,65}$ it therefore should preferentially be used in PHPT patients with renal impairment and in renal HPT patients.

\section{Other benefits of hormone measuring in primary hyperparathyroidism surgery}

\section{Prediction of recurrence}

In their study of the predictors of recurrence following surgery for PHPT, Schneider and colleagues ${ }^{66}$ interestingly reported that the greater percent IOPTH decline was not only protective against, but also significantly predictive of, recurrence. In the latter study, a threshold of $63 \%$ decline was statistically generated as the best value able to predict recurrence, with a sensitivity of $72.7 \%$. In their study of IOPTH kinetics, the same authors ${ }^{67}$ identified an unusual "rebound" pattern in $6.2 \%$ of operated PHPT cases, in which the PTH level rose by more than $5 \mathrm{pg} / \mathrm{ml}$ after achieving $50 \%$ reduction in a preceding measurement. The latter pattern was reported to be significantly associated with higher recurrence rate.

\section{Prediction of post-parathyroidectomy} hypocalcemia

In a similar fashion to its ability to predict postparathyroidectomy normocalcemia and post-thyroidectomy hypocalcemia, a few researchers have tested several endpoints derived from IPM for their potential ability to predict post-parathyroidectomy hypocalcemia. In their analysis of a prospectively recorded database of 68 PHPT patients who underwent reoperation, Elaraj et al ${ }^{68}$ found that in patients with MGD, an IOPTH drop of $84 \%$ or more was significantly correlated with occurrence of postoperative hypocalcemia. Shoman and colleagues ${ }^{69}$ have also found that the percentage of IOPTH drop between the pre-incision and the $10 \mathrm{~min}$ post-excision values can significantly predict whether postoperative hypocalcemia may develop. Similar correlations have not, however, been subsequently found in other authors' reports ${ }^{70}$ indicating that further studies, preferably on larger patient samples, are required. If post-parathyroidectomy hypocalcemia could be anticipated intraoperatively, certain management decisions would be affected: parathyroid auto-transplantation, calcium supplementation and frequency of follow-ups. 
An intraoperative lateralizing aid

A 5\% or higher difference in PTH levels between both internal jugular veins at the start of surgery has been reported to be a safe and efficient lateralization method, particularly useful in PHPT patients with negative preoperative localizing studies or suspected MGD disease. ${ }^{71,72}$ A similar technique has been successfully used to localize undescended parathyroid adenoma after failed BNE and intraoperative ultrasonography. ${ }^{73}$

\section{Useful adjunct to perioperative tools}

In order to optimize the outcomes of parathyroid surgery, IPM has also been employed as an adjunct to other perioperative tools. Table 2 demonstrates the usefulness of measuring IOPTH in improving the performance of other perioperative tools for PHPT patients undergoing parathyroid surgery.

Potential alternative to other intraoperative tools

In comparison to other intraoperative tools, IPM has been shown to have higher performance measures. In view of cost savings, it is possible for IPM to replace rather than to supplement other aids, namely frozen section (FS) and intraoperative gamma probe (GP).

As an intraoperative adjunct, FS has been used to confirm the identity of the excised tissue as parathyroid so as to identify it as the culprit and to exclude the possibility of tissue being hyperplastic rather than adenomatous. ${ }^{79}$ However, in terms of assuring the surgical adequacy, it is more reasonable to have some sort of functional rather than morphologic confirmation. In their PHPT case series, Tampi et al ${ }^{80}$ demonstrated the superiority of IPM to FS, since the former was able to confirm the excision of "adenoma" in all cases, while the latter demonstrated hypercellularity "adenoma vs hyperplasia" in five cases. The inconsistent diagnostic accuracy of FS in fact challenges its usefulness in surgical decision-making. ${ }^{81}$ Quick PTH assays can help confirm excision of the offending gland, not only through picking a satisfactory PTH reduction with a high accuracy but also through measuring hormone levels in suspected specimens (discussed later). Thus, IPM has been termed "biochemical FS" and has been suggested as a replacement for the traditional histopathological FS. ${ }^{82}$

Similarly, in a comprehensive prospective evaluation of intraoperative parathyroid surgery adjuncts, IPM has been reported to be a more reliable tool when compared to gamma probe in terms of sensitivity, PPV and accuracy $(99 \%, 100 \%$ and $98 \%$ vs $93 \%$, $89 \%$ and $83 \%$, respectively). ${ }^{83}$ The latter findings may therefore suggest the possibility of IPM-guided MIP replacing minimally invasive radioguided parathyroidectomy (MIRP).

\section{Intraoperative parathyroid hormone measuring in suspected tissue}

\section{Confirming the parathyroid identity of excised tissue}

Despite the fairly accurate results of IPM recorded

Table 2. Role of IPM in enhancing the performance of other perioperative parathyroid adjuncts

\begin{tabular}{|c|c|c|c|c|c|c|c|c|}
\hline $\begin{array}{l}\text { Entire } \\
\text { cohort }\end{array}$ & Subgroup & $\begin{array}{c}\text { Subgroup } \\
\text { description }\end{array}$ & Tool & Measure & Parameter & $\begin{array}{l}\text { Without } \\
\text { IOPTH }\end{array}$ & $\begin{array}{c}\text { With } \\
\text { IOPTH }\end{array}$ & Ref \\
\hline \multicolumn{9}{|c|}{ Pre-operative tools } \\
\hline 54 & 50 & SA & MIBI & Sensitivity & Confirming SA & $90 \%$ & $100 \%$ & (74) \\
\hline 287 & 21 & $\mathrm{DA}$ & MIBI/US & Accuracy & Predicting DA & $60 \%$ & $80 \%$ & (75) \\
\hline 233 & 23 & MGD & MIBI/US & Sensitivity & Detection of MGD & $30 \%$ & $89 \%$ & $(50)$ \\
\hline \multicolumn{9}{|c|}{ Intraoperative tools } \\
\hline 78 & 50 & SA & Intraop US & Sensitivity & Detection of SA & $33 \%$ & $65 \%$ & (76) \\
\hline 51 & 51 & $\begin{array}{l}\text { Had MIBI } \\
\& \text { MIRS }\end{array}$ & Intraop GP/MIBI & Success rate & $\begin{array}{l}\text { Achieving postoperative } \\
\text { normocalcemia }\end{array}$ & $92 \%$ & $100 \%$ & (77) \\
\hline 211 & 19 & Hyperplasia & Intraop FS & Sensitivity & Detecting hyperplasia & $53 \%$ & $74 \%$ & (78) \\
\hline
\end{tabular}

SA: single adenoma; DA: double adenoma; MGD: multiglandular disease; MIBI: Methoxy Iso Butyl Isonitrile; US: ultrasound; MIRS: minimally invasive radioguided surgery; GP: gamma probe, FS: frozen section. 
in most of the literature, occurrence of false results, though uncommon, is still very problematic on account of its grave consequences, namely, unnecessary explorations with consequent morbidity (in the event of a false negative) or leaving behind pathologic parathyroid tissue, ultimately resulting in persistence HPT (in the event of a false positive). Hence, other techniques for confirming the parathyroid nature of the removed specimen continue to be sought. Rapid PTH measurement in needle aspirate from the excised suspected tissue has been reported to be an efficient method of confirming the parathyroid identity with 97\% sensitivity and 100\% specificity (PHPT). ${ }^{84}$ The accuracy of a PTH assay in distinguishing the parathyroid tissue has been reported to be affected by the number of needle passes, with 5 passes being optimal to achieve a minimum of false negatives. ${ }^{85}$ Moreover, measuring PTH level in $1 \mathrm{~mm}$ biopsy of the tissue in question has demonstrated an accuracy of $99 \%$ in identifying parathyroid tissue, exceeding the accuracy of PTH determination in FNA aspirates. ${ }^{86}$ Such "biochemical frozen section" may provide a time-effective and cost-effective alternative to the traditional one, particularly if quick PTH settings have already been set for IPM. ${ }^{87}$

\section{Differentiation between normal and pathological parathyroids}

In PHPT cases in which BNEs are deemed necessary, surgeon experience has been recognized to be of utmost importance in picking out the pathologic gland. Occasionally, the pathologic gland(s) may be of borderline size and be difficult to distinguish from normal glands. A useful adjunct in this case would be measuring the PTH in a needle aspirate from the suspicious glands, this measurement having been reported to make an efficient differentiation $(<100$ vs $>1000 \mathrm{pg} / \mathrm{ml}){ }^{88}$

\section{IN-THEATRE USE OF QPTH ASSAYS IN THYROID SURGERY}

\section{Prediction of the post-thyroidectomy calcemic state}

The prediction of post-thyroidectomy hyocalcemia has been the subject of extensive research, since this would significantly impact subsequent management. An optimal predictor should be capable of early, accurate and measurable prediction. Although some demographic (e.g. age, gender and race) and pathobiologic (e.g. thyroid pathology, surgery extent) factors can significantly predict post-thyroidectomy hypocalcemia, no single factor among these has demonstrated a measurable performance..$^{89}$ Nomograms integrating some of these factors can indeed quantitatively predict post-thyroidectomy hypocalcemia at a fairly early stage; however unfortunately, the overall reported accuracy was only $67.7 \% .^{90}$

Biochemical factors, in terms of perioperative $\mathrm{Ca}$ and PTH, have been extensively studied as candidate predictors. Although a postoperative $24 \mathrm{~h}$ percent $\mathrm{Ca}$ drop ${ }^{91}$ or $16 \mathrm{~h}$ low adjusted $\mathrm{Ca}^{92}$ could quantitatively predict post-thyroidectomy hypocalcemia with high accuracy ( 87 and $90 \%$, respectively), unfortunately, by that time, a symptomatic hypocalcemic episode may already have occurred. In contrast, measuring PTH intraoperatively seems to fulfil the requirements of an ideal predictor of post-thyroidectomy hypocalcemia, with the percentage of PTH drop being reported to be more accurate than PTH absolute value $(88 \%$ vs $72 \%) .{ }^{92}$ In their analysis of 249 patients, Noordzi et $\mathrm{al}^{93}$ demonstrated that IOPTH can predict postthyroidectomy hypocalcemia with the sensitivity incrementing from $34 \%$ to $93.6 \%$ as the cut-off of the percentage of PTH decline decreased from $90 \%$ to $40 \%$ within 20 min after gland removal. Such early prediction can potentially guide important clinical decisions: 1 ) a second look at the excised thyroidectomy specimen, should a parathyroid gland be inadvertently removed, 2) determination as to whether parathyroid auto-transplantation is necessary, 3) timing of discharge and 4) early consideration of $\mathrm{Ca}$ supplementation in those patients identified as being at risk.

\section{Differentiating parathyroid and non-parathyroid tissue}

During thyroid surgery, some tissues (thyroid nodules or lymph nodes) can occasionally be confused with parathyroids, which can present a challenging situation. On the one hand, preserving these tissues may compromise the completeness of resection, while, on the other hand, excising them may expose the patient to the risk of hypoparathyroidism. Rapid intraoperative measurement of PTH in FNA aspirates of suspicious tissue has been reported to be a reliable 
and simple method of differentiating parathyroid and non-parathyroid tisuue..$^{88,94,95}$ This could provide an alternative to FS examination, dodging the injurious effect of the bioptic process and achieving similar or even more accurate results. ${ }^{96} \mathrm{~A}$ recently reported modification of the IOPTH assay achieved 100\% sensitivity and $100 \%$ specificity in distinguishing parathyroid from non-parathyroid tissues within ultra-short turnaround time (60 seconds) and could potentially replace frozen-section assessment. ${ }^{97}$

\section{OUT-OF-THEATRE USE OF QPTH ASSAYS}

\section{In the post-anesthesia care unit (PACU)}

Rapid PTH testing has also found other useful applications outside the theatre. McLeod and colleagues ${ }^{98}$ have proposed testing PTH in the PACU for post-thyroidectomy patients with a cut-off PTH value $<12 \mathrm{pg} / \mathrm{ml}$ or PTH drop $>75 \%$, achieving a sensitivity and specificity of $100 \%, 92 \%$ and $100 \%, 88 \%$, respectively, for prediction of post-thyroidectomy hypocalcemia. Subsequently, Sabour and colleagues ${ }^{99}$ recommended initiating $\mathrm{Ca} / \mathrm{Vit} \mathrm{D}$ therapy on a selective basis for those whose PACU-PTH reads less than 15 with the aim of reducing the rate of postthyroidectomy hypocalcemia Such an approach is superior to routine supplementation on account of the achievement of a lower rate of hypercalcemia, better patient compliance and lower cost.

\section{In the radiology suite}

The rapid PTH assay for samples collected by image-guided super-selective venous sampling (SVS) can provide a near-real time PTH level in cervical veins, leading to correct lateralization of the culprit lesion in $83 \%-93 \%$ of cases that have a significant gradient. ${ }^{100-102}$ Alternatively, safer and less timeconsuming non-SVS has also been used to detect a localizing parathyroid gradient augmented through employing a systemic hypocalcemic challenge. ${ }^{103}$ Similarly, using rapid assay for measuring PTH in US-guided fine needle aspirate from a suspicious parathyroid lesion has also been reported to be an efficient method of localization. ${ }^{104}$ These techniques have proved useful in preoperatively lateralizing the culprit lesion particularly for recurrent or persistent HPT with non-informative conventional scans, i.e. a negative or equivocal result, thus improving subse- quent surgery and even allowing it to be performed through MIP.

\section{In the endoscopy suite}

Interestingly, Graff-Baker and colleagues ${ }^{105}$ have reported the use of a rapid PTH assay for measuring the PTH value in a mediastinal mass suspected to be an ectopic parathyroid gland in an old man with medical comorbidities. In this case, aspirate was obtained by endoscopic US-guided fine needle and revealed a very high PTH level, thus confirming the parathyroid nature of the lesion and justifying major surgery in such a high-risk patient.

\section{In the outpatient setting}

Rapid PTH assays in US-guided aspirates from suspected parathyroid lesions have been reported to significantly improve sensitivity of localizing the truly offending gland from $67.7 \%$ to $91.9 \%$ when compared to US-alone-based localization, subsequently impacting the management decision in the early pre-admission phase. ${ }^{106}$

\section{CONCLUSIONS AND RECOMMENDATIONS}

The role of IPM in guiding surgery for PHPT is more or less well established. However, its role in renal HPT surgery needs to be further investigated, particularly concerning whether it could efficiently guide MAS and which IOPTH endpoint would achieve the best performance. Bio-intact, rather than intact, PTH assays should preferentially be used for intraoperative hormone monitoring in renal patients. In order to validate its use as a biochemical frozen section, potentially replacing the traditional histopathological section, prospectively designed comparative studies on large patient samples are needed to provide an adequate level of evidence. For its advantageous capability of predicting a post-thyroidectomy calcemic state, quickly measuring PTH at skin closure time should be standardized and validated for relevant decision-making. The usefulness of quick PTH assays in the clinical setting emphasize the importance of multidisciplinary teamwork, including surgeons, anesthetists, physicians and biochemists, in providing optimal care for the endocrine patient. Furthermore, given the reviewed wide range of clinical applications, it is worthy for manufacturers and companies 
to collaborate with researchers and health institutions to develop newer PTH measuring platforms that will provide better accuracy, more time- and cost effectiveness as well as user friendly interface.

\section{ACKNOWLEDGEMENT}

M.S.S. would like to thank the Ministry of Higher Education- Missions sector, Egypt and the British Council for their support through Newton-Musharafa programme via the Egyptian Cultural Bureau in London.

\section{CONFLICT OF INTEREST STATEMENT}

Author declares that he has no conflict of interest.

\section{REFERENCES}

1. Sokoll LJ, Wians FH Jr, Remaley AT, 2004 Rapid intraoperative immunoassay of parathyroid hormone and other hormones: a new paradigm for point-of-care testing. Clin Chem 50: 1126-1135.

2. Point-of-Care Testing Guideline Published by CLSI, 2010 Laboratory Medicine 41: 499-500.

3. Sadeghi N, Akin E, Lee JY, Roland J, Knoll S, 2008 Targeted parathyroidectomy: effectiveness and intraoperative rapid-parathormone dynamics. Laryngoscope 118: 1997-2002.

4. Calva-Cerqueira D, Smith BJ, Hostetler ML, et al, 2007 Minimally invasive parathyroidectomy and preoperative MIBI scans: correlation of gland weight and preoperative PTH. J Am Coll Surg 205: Suppl: 38-44.

5. Jortay AM, Verougstraete G, Wittersheim E, Hooghe L, Bisschop P, Bergmann P, 2004 Intraoperative measurement of parathyroid hormone in minimally invasive surgery for parathyroid adenoma. Acta Otorhinolaryngol Belg 58: 125-128.

6. Kumar R, Thompson JR, 2011 The regulation of parathyroid hormone secretion and synthesis. J Am Soc Nephrol 22: 216-224.

7. Bieglmayer C, Prager G, Niederle B, 2002 Kinetic analyses of parathyroid hormone clearance as measured by three rapid immunoassays during parathyroidectomy. Clin Chem 48: 1731-1738.

8. Barczynski M, Konturek A, Hubalewska-Dydejczyk A, Cichon S, Nowak W, 2009 Evaluation of Halle, Miami, Rome, and Vienna intraoperative iPTH assay criteria in guiding minimally invasive parathyroidectomy. Langenbecks Arch Surg 394: 843-849.

9. Carneiro DM, Solorzano CC, Nader MC, Ramirez M, Irvin GL 3rd, 2003 Comparison of intraoperative iPTH assay (QPTH) criteria in guiding parathyroidectomy: which criterion is the most accurate? Surgery 134: 973-981.

10. Day KM, Elsayed M, Monchik JM, 2015 No Need to Abandon Focused Unilateral Exploration for Primary Hyperparathyroidism with Intraoperative Monitoring of Intact Parathyroid Hormone. J Am Coll Surg 221: 518-523.

11. Rajaei MH, Oltmann SC, Adkisson CD, et al, 2014 Is intraoperative parathyroid hormone monitoring necessary with ipsilateral parathyroid gland visualization during anticipated unilateral exploration for primary hyperparathyroidism: a two-institution analysis of more than 2,000 patients. Surgery 156: 760-766.

12. Rosen D, Pribitkin E A, Sciarrino J, 2012 MinimallyInvasive Parathyroid Surgery, INTECH Open Access Publisher.

13. Noureldine SI, Lewing N, Tufano RP, Kandil E, 2014 The Role of the Robotic-Assisted Transaxillary Gasless Approach for the Removal of Parathyroid Adenomas. J Otorhinolaryngol Relat Spec 76: 19-24.

14. Ismail M, Maza S, Swierzy M, et al, 2010 Resection of ectopic mediastinal parathyroid glands with the da Vincirobotic system. Br J Surg 97: 337-343.

15. Swierzy M, Ismail M, Ruckert JC, 2010 Robotic surgery for ectopic mediastinal parathyroid glands. Innovations (Phila) 5: 203-204.

16. Van Dessel E, Hendriks J, Lauwers P, Ysebaert D, Van Schil P, 2010 Mediastinal Parathyroidectomy with the da Vinci Robot. Innovations (Phila) 5: 204.

17. Udelsman R, Donovan PI, 2004 Open minimally invasive parathyroid surgery. World J Surg 28: 1224-1226.

18. Faiz Z, Baas PC, Kelder W, 2013 Minimally invasive parathyroidectomy seems suitable for day surgery in patients with primary hyperparathyroidism. Eur $\mathbf{J}$ Cancer 49: S766-S767.

19. Lee S, Ryu H, Morris LF, et al, 2014 Operative failure in minimally invasive parathyroidectomy utilizing an intraoperative parathyroid hormone assay. Ann Surg Oncol 21: 1878-1883.

20. Carneiro DM, Solorzano CC, Irvin GL 3rd, 2004 Recurrent disease after limited parathyroidectomy for sporadic primary hyperparathyroidism. J Am Coll Surg 199: 849-853.

21. Grant CS, Thompson G, Farley D, Van Heerden J, 2005 Primary hyperparathyroidism surgical management since the introduction of minimally invasive parathyroidectomy: Mayo Clinic experience. Arch Surg 140: 472-479.

22. Komolafe OO, McMinn AG, Doughty JC, Wilson CR, 2009 Parathyroid carcinoma. Mini-series of patientssuccessfully treated with minimally invasive surgery using intra-operative PTH assays, and literature review. Scott Med J 54: 58.

23. Udelsman R, Donovan PI, 2006 Remedial parathyroid surgery: changing trends in 130 consecutive cases. Ann Surg 244: 471-479. 
24. Yen TW, Wang TS, Doffek KM, Krzywda EA, Wilson SD, 2008 Reoperative parathyroidectomy: an algorithm for imaging and monitoring of intraoperative parathyroid hormone levels that results in a successful focused approach. Surgery 144: 611-621

25. Miccoli P, Minuto M, Cetani F, Ambrosini CE, Berti P, 2005 Familial parathyroid hyperplasia: is there a place for minimally invasive surgery? Description of the first treated case. J Endocrinol Invest 28: 942-943.

26. Rahbari R, Sansano IG, Elaraj DM, Duh QY, Clark $\mathrm{OH}$, Kebebew E, 2010 Prior head and neck radiation exposure is not a contraindication to minimally invasive parathyroidectomy. J Am Coll Surg 210: 942-948.

27. Sukumar MS, Komanapalli CB, Cohen JI, 2006 Minimally invasive management of the mediastinal parathyroid adenoma. Laryngoscope 116: 482-487.

28. Chae AW, Perricone A, Brumund KT, Bouvet M, 2008 Outpatient video-assisted thoracoscopic surgery (VATS) for ectopic mediastinal parathyroid adenoma: a case report and review of the literature. J Laparoendosc Adv Surg Tech A 18: 383-390.

29. Schulte KM, Cupisti K, Dotzenrath C, Schabram J, Roher HD, 2003 The actual role of classic bilateral cervicotomic approach for primary hyperparathyroidism in the era of minimally invasive surgery. Ann Ital Chir 74: 389-393.

30. Pitt SC, Sippel RS, Chen H, 2009 Secondary and tertiary hyperparathyroidism, state of the art surgical management. Surg Clin North Am 89: 1227-1239.

31. Özmen T, Manukyan M, Şen S, Kahveci A, Yeğen C, Güllüoğlu BM, 2014 Is three-gland-or-less parathyroidectomy a clinical failure for secondary hyperparathyroidism? Turkish J Surg 30: 201-206.

32. Muller-Stich BP, Brandle M, Binet I, Warschkow R, Lange J, Clerici T, 2007 To autotransplant simultaneously or not -- can intraoperative parathyroid hormone monitoring reliably predict early postoperative parathyroid hormone levels after total parathyroidectomy for hyperplasia? Surgery 142: 47-56.

33. Moor JW, Roberts S, Atkin SL, England RJ, 2011 Intraoperative parathyroid hormone monitoring to determine long-term success of total parathyroidectomy for secondary hyperparathyroidism. Head Neck 33: 293-296.

34. Miccoli P, Materazzi G, Berti P, 2009 Minimally invasive video-assisted thyroidectomy and parathyroidectomy. World 1: 27-29.

35. Alesina PF, Hinrichs J, Kribben A, Walz MK, 2010 Minimally invasive video-assisted parathyroidectomy (MIVAP) for secondary hyperparathyroidism: report of initial experience. Am J Surg 199: 851-855.

36. Mourad M, Ngongang C, Saab N, et al, 2001 Videoassisted neck exploration for primary and secondary hyperparathyroidism: initial experience. Surg Endosc 15: 1112-1115.

37. Nawrot I, Chudziński W, Ciąćka T, Barczyński M,
Szmidt J, 2014 Reoperations for Persistent or Recurrent Primary Hyperparathyroidism: Results of a Retrospective Cohort Study at a Tertiary Referral Center. Med Sci Monit 20: 1604-1612.

38. Lew JI, Solorzano CC, Montano RE, Carneiro-Pla DM, Irvin GL, 3rd, 2008 Role of intraoperative parathormone monitoring during parathyroidectomy in patients with discordant localization studies. Surgery 144: 299-306.

39. Phitayakorn R, Mchenry CR, 2006 Incidence and location of ectopic abnormal parathyroid glands. Am J Surg 191: 418-423.

40. Mohebati A, Shaha A, 2012 Anatomy of thyroid and parathyroid glands and neurovascular relations. Clinical Anatomy 25: 19-31.

41. Uludag M, Isgor A, Yetkin G, Atay M, Kebudi A, Akgun I, 2009 Supernumerary ectopic parathyroid glands. Persistent hyperparathyroidism due to mediastinal parathyroid adenoma localized by preoperative single photon emission computed tomography and intraoperative gamma probe application. Hormones (Athens) 8: 144-149.

42. Henry JF, Defechereux T, Raffaelli M, Lubrano D, Iacobone M, 2000 Supernumerary ectopic hyperfunctioning parathyroid gland: a potential pitfall in surgery for sporadic primary hyperthyroidism. Ann Chir 125: 247-252.

43. Okada M, Tominaga Y, Yamamoto T, Hiramitsu T, Narumi S, Watarai Y, 2016 Location Frequency of Missed Parathyroid Glands After Parathyroidectomy in Patients with Persistent or Recurrent Secondary Hyperparathyroidism. World J Surg 40: 595-599.

44. Shen W, Duren M, Morita E, et al, 1996 Reoperation for persistent or recurrent primary hyperparathyroidism. Arch Surg 131: 861-867; discussion 867-869.

45. Mariette C, Pellissier L, Combemale F, Quievreux JL, Carnaille B, Proye C, 1998 Reoperation for persistent or recurrent primary hyperparathyroidism. Langenbecks Arch Surg 383: 174-179.

46. Hoda NE, Phillips P, Ahmed N, 2013 Recommendations after non-localizing sestamibi and ultrasound scans in primary hyperparathyroid disease: order more scans or explore surgically? Journal of the Mississippi State Medical Association 54: 36-41.

47. Elizondo ME, Díaz-Aguirregoitia FJ, Amondarain JA, Vidaur F, 2005 Intraoperative monitoring of intact PTH in surgery for renal hyperparathyroidism as an indicator of complete parathyroid removal. World J Surg 29: 1504-1509.

48. Alhefdhi A, Schneider DF, Sippel R, Chen H, 2014 Recurrent and persistence primary hyperparathyroidism occurs more frequently in patients with double adenomas. J Surg Res 190: 198-202.

49. Gauger PG, Mullan MH, Thompson NW, Doherty GM, Matz KA, England BG, 2004 An alternative analysis of intraoperative parathyroid hormone data may improve the ability to detect multiglandular disease. Arch Surg 
139: 164-169.

50. Sugg SL, Krzywda EA, Demeure MJ, Wilson SD, 2004 Detection of multiple gland primary hyperparathyroidism in the era of minimally invasive parathyroidectomy. Surgery 136: 1303-1309.

51. Solórzano CC, Carneiro-Pla DM, Lew IJ, Rodgers SE, Montano R, Irvin GL, 2007 Intra-operative Parathyroid Hormone Monitoring in Patients with Parathyroid Cancer. Ann Surg Oncol 14: 3216-3222.

52. Adam MA, Untch BR, Olson JA, Jr, 2010 Parathyroid carcinoma: current understanding and new insights into gene expression and intraoperative parathyroid hormone kinetics. Oncologist 15: 61-72.

53. Irvin GL, 3rd, Molinari AS, Figueroa C, Carneiro DM, 1999 Improved success rate in reoperative parathyroidectomy with intraoperative PTH assay. Ann Surg 229: 874-878; discussion 878-879.

54. Agarwal G, Barakate MS, Robinson B, et al, 2001 Intraoperative quick parathyroid hormone versus sameday parathyroid hormone testing for minimally invasive parathyroidectomy: a cost-effectiveness study. Surgery 130: 963-970.

55. Irvin GL, 3rd, Solorzano CC, Carneiro DM, 2004 Quick intraoperative parathyroid hormone assay: surgical adjunct to allow limited parathyroidectomy, improve success rate, and predict outcome. World J Surg 28: 1287-1292.

56. Chen H, Pruhs Z, Starling JR, Mack E, 2005 Intraoperative parathyroid hormone testing improves cure rates in patients undergoing minimally invasive parathyroidectomy. Surgery 138: 583-587; discussion 587-590.

57. Barczynski M, Konturek A, Cichon S, HubalewskaDydejczyk A, Golkowski F, Huszno B, 2007 Intraoperative parathyroid hormone assay improves outcomes of minimally invasive parathyroidectomy mainly in patients with a presumed solitary parathyroid adenoma and missing concordance of preoperative imaging. Clin Endocrinol (Oxf) 66: 878-885.

58. Sugino K, Nagahama M, Kitagawa W, et al, 2010 Minimally invasive surgery for primary hyperparathyroidism with or without intraoperative parathyroid hormone monitoring. Endocrine Journal 57: 953-958.

59. Kim HG, Kim WY, Woo SU, Lee JB, Lee Y-M, 2015 Minimally invasive parathyroidectomy with or without intraoperative parathyroid hormone for primary hyperparathyroidism. Annals of Surgical Treatment and Research 89: 111-116.

60. Gasparri G, Camandona M, Bertoldo U, et al, 2009 The usefulness of preoperative dual-phase 99mTc MIBIscintigraphy and IO-PTH assay in the treatment of secondary and tertiary hyperparathyroidism. Ann Surg 250: 868-871.

61. Taniguchi M, Tanaka M, Hamano T, et al, 2011 Comparison between whole and intact parathyroid hormone assays. Ther Apher Dial 15: Suppl 1: 42-49.

62. Yamashita H, Gao P, Cantor T, et al, 2004 Comparison of parathyroid hormone levels from the intact and whole parathyroid hormone assays after parathyroidectomy for primary and secondary hyperparathyroidism. Surgery 135: 149-156.

63. Ikeda Y, Kurihara H, Morita N, Miyabe R, Takami H, 2007 The role of quick bio-intact PTH(1-84) assay during parathyroidectomy for secondary hyperparathyroidism. J Surg Res 141: 306-310.

64. Kaczirek K, Prager G, Riss P, et al, 2006 Novel parathyroid hormone (1-84) assay as basis for parathyroid hormone monitoring in renal hyperparathyroidism. Arch Surg 141: 129-134.

65. Yamashita H, Cantor T, Uchino S, et al, 2005 Sequential changes in plasma intact and whole parathyroid hormone levels during parathyroidectomy for secondary hyperparathyroidism. World J Surg 29: 169-173.

66. Schneider DF, Mazeh H, Chen H, Sippel RS, 2014 Predictors of recurrence in primary hyperparathyroidism: an analysis of 1386 cases. Ann Surg 259: 563-568.

67. Schneider DF, Ojomo KA, Mazeh H, Oltmann SC, Sippel RS, Chen H, 2013 Significance of rebounding parathyroid hormone levels during parathyroidectomy. J Surg Res 184: 265-268.

68. Elaraj DM, Remaley AT, Simonds WF, et al, 2002 Utility of rapid intraoperative parathyroid hormone assay to predict severe postoperative hypocalcemia after reoperation for hyperparathyroidism. Surgery 132: 1028-1034.

69. Shoman N, Melck A, Holmes D, et al, 2008 Utility of intraoperative parathyroid hormone measurement in predicting postparathyroidectomy hypocalcemia. $\mathrm{J}$ Otolaryngol Head Neck Surg 37: 16-22.

70. Stepansky A, Gold-Deutch R, Poluksht N, et al, 2010 Intraoperative parathormone measurements and postoperative hypocalcemia. Isr Med Assoc J 12: 207-210.

71. Ito F, Sippel R, Lederman J, Chen H, 2007 The utility of intraoperative bilateral internal jugular venous sampling with rapid parathyroid hormone testing. Ann Surg 245: 959-963.

72. Maceri DR, Kokot N, Green K, Montgomery V, Sharifi J, 2011 Split central venous sampling of parathyroid hormone: An adjunct to surgical exploration. Head Neck 33: 1715-1718.

73. Lee LS, Canter RJ, Fraker DL, 2006 Intraoperative jugular venous sampling AIDS detection of an undescended parathyroid adenoma. World J Surg 30: 620-623.

74. Miller P, Kindred A, Kosoy D, et al, 2003 Preoperative sestamibi localization combined with intraoperative parathyroid hormone assay predicts successful focused unilateral neck exploration during surgery for primary hyperparathyroidism. Am Surg 69: 82-85.

75. Haciyanli M, Lal G, Morita E, Duh QY, Kebebew E, Clark OH, 2003 Accuracy of preoperative localization studies and intraoperative parathyroid hormone assay in patients with primary hyperparathyroidism and double 
adenoma. J Am Coll Surg 197: 739-746.

76. Barczynski M, Konturek A, Hubalewska-Dydejczyk A, Cichon S, Nowak W, 2009 Utility of intraoperative bilateral internal jugular venous sampling with rapid parathyroid hormone testing in guiding patients with a negative sestamibi scan for minimally invasive parathyroidectomy--a randomized controlled trial. Langenbecks Arch Surg 394: 827-835.

77. Hanif F, Coffey J C, Romics L Jr, O'sullivan K, Aftab F, Redmond HP, 2006 Rapid intraoperative parathyroid hormone assay--more than just a comfort measure. World J Surg 30: 156-161.

78. Zawawi F, Mlynarek AM, Cantor A, et al, 2013 Intraoperative parathyroid hormone level in parathyroidectomy: which patients benefit from it? J Otolaryngol Head Neck Surg 42: 56.

79. Westra WH, Pritchett DD, Udelsman R, 1998 Intraoperative confirmation of parathyroid tissue during parathyroid exploration: a retrospective evaluation of the frozen section. American J Surg Pathol 22: 538-544.

80. Tampi C, Chavan N, Parikh D, 2014 Intraoperative parathyroid hormone assay-cutting the Gordian knot. Indian J Endocrinol Metab 18: 210-212.

81. Irvin I ii GL, Carneiro DM, 2000 Management changes in primary hyperparathyroidism. JAMA 284: 934-936.

82. Farrag T, Weinberger P, Seybt M, Terris DJ, 2011 Pointof-care rapid intraoperative parathyroid hormone assay of needle aspirates from parathyroid tissue: a substitute for frozen sections. Am J Otolaryngol 32: 574-577.

83. Chen H, Mack E, Starling JR, 2005 A comprehensive evaluation of perioperative adjuncts during minimally invasive parathyroidectomy: which is most reliable? Ann Surg 242: 375-383.

84. Chan RK, Ibrahim SI, Pil P, Tanasijevic M, Moore FD, 2005 Validation of a method to replace frozen section during parathyroid exploration by using the rapid parathyroid hormone assay on parathyroid aspirates. Arch Surg 140: 371-373.

85. Guerrero MA, Suh I, Vriens MR, et al, 2010 The number of needle passes affects the accuracy of parathyroid hormone assay with intraoperative parathyroid aspiration. Am J Surg 200: 701-706.

86. Conrad DN, Olson JE, Hartwig HM, Mack E, Chen H, 2006 A prospective evaluation of novel methods to intraoperatively distinguish parathyroid tissue utilizing a parathyroid hormone assay. J Surg Res 133: 38-41.

87. Lo CY, Chan WF, Leung P, Luk JM, 2005 Applicability of tissue aspirate for quick parathyroid hormone assay to confirm parathyroid tissue identity during parathyroidectomy for primary hyperparathyroidism. Arch Surg 140: 146-150.

88. Kiblut NK, Cussac JF, Soudan B, et al, 2004 Fine needle aspiration and intraparathyroid intact parathyroid hormone measurement for reoperative parathyroid surgery. World J Surg 28: 1143-1147.

89. Baldassarre RL, Chang DC, Brumund KT, Bouvet M,
2012 Predictors of Hypocalcemia after Thyroidectomy: Results from the Nationwide Inpatient Sample. ISRN Surgery 2012: 838614.

90. Ali S, Yu C, Palmer FL, et al, 2011 Nomogram to aid selection of patients for short-stay thyroidectomy based on risk of postoperative hypocalcemia. Arch Otolaryngol Head Neck Surg 137: 1154-1160.

91. Lang BH, Yih PC, Ng KK, 2012 A prospective evaluation of quick intraoperative parathyroid hormone assay at the time of skin closure in predicting clinically relevant hypocalcemia after thyroidectomy. World J Surg 36: 1300-1306.

92. Cavicchi O, Piccin O, Caliceti U, et al, 2008 Accuracy of PTH assay and corrected calcium in early prediction of hypoparathyroidism after thyroid surgery. Otolaryngol Head Neck Surg 138: 594-600.

93. Noordzij JP, Lee SL, Bernet VJ, et al, 2007 Early prediction of hypocalcemia after thyroidectomy using parathyroid hormone: an analysis of pooled individual patient data from nine observational studies. J Am Coll Surg 205: 748-754.

94. Bian X-H, Zhang G, Zhang C-H, et al, 2015 Rapid intraoperative parathyroid hormone assay through fine needle aspiration for identification of parathyroid in thyroid surgery. European Surgery Acta Chirurgica Austriaca. Conference: 8th Annual Meeting of Chinese College of Surgeons and 19th Annual Meeting of the European Society of Surgery Beijing China. Conference Start 47.

95. Pelizzo MR, Losi A, Boschin IM, et al, 2010 Rapid intraoperative parathyroid hormone assay in fine needle aspiration for differential diagnosis in thyroid and parathyroid surgery. Clin Chem Lab Med 48: 1313-1317.

96. Guerrero MA, Vriens MR, Suh I, Khanafshar E, Clark $\mathrm{OH}, 2009$ Intraoperative diagnostic strategy to distinguish parathyroid adenomas from metastatic thyroid cancer. Endocr Pract 15: 454-457.

97. James BC, Nagar S, Tracy M, et al, 2014 A novel, ultrarapid parathyroid hormone assay to distinguish parathyroid from nonparathyroid tissue. Surgery 156 : 1638-12643.

98. Mcleod IK, Arciero C, Noordzij JP, et al, 2006 The use of rapid parathyroid hormone assay in predicting postoperative hypocalcemia after total or completion thyroidectomy. Thyroid 16: 259-265.

99. Sabour S, Manders E, Steward DL, 2009 The role of rapid PACU parathyroid hormone in reducing postthyroidectomy hypocalcemia. Otolaryngol Head Neck Surg 141: 727-729.

100. Lebastchi AH, Aruny JE, Donovan PI, et al, 2015 RealTime Super Selective Venous Sampling in Remedial Parathyroid Surgery. J Am Coll Surg 220: 994-1000.

101. Udelsman R, Aruny JE, Donovan PI, et al, 2003 Rapid parathyroid hormone analysis during venous localization. Ann Surg 237: 714-721.

102. Mindel JR, Venbrux AC, Knoll SM, Cohen JL, 2011 
Preoperative parathyroid venous sampling in patients with non-localizing primary hyperparathyroidism. Endocr Rev 32 (3 Meeting Abstracts).

103. Morris LF, Loh C, Ro K, et al, 2012 Non-super-selective venous sampling for persistent hyperparathyroidism using a systemic hypocalcemic challenge. J Vasc Interv Radiol 23: 1191-1199.

104. Maser C, Donovan P, Santos F, et al, 2006 Sonographically guided fine needle aspiration with rapid parathyroid hormone assay. Ann Surg Oncol 13: 1690-1695.

105. Graff-Baker A, Roman SA, Boffa D, Aslanian H, Sosa
JA, 2009 Diagnosis of Ectopic Middle Mediastinal Parathyroid Adenoma Using Endoscopic Ultrasonography-Guided Fine-Needle Aspiration with Real-Time Rapid Parathyroid Hormone Assay. J Am Coll Surg 209: e1-e4.

106. Barczynski M, Golkowski F, Konturek A, et al, 2006 Technetium-99m-sestamibi subtraction scintigraphy vs. ultrasonography combined with a rapid parathyroid hormone assay in parathyroid aspirates in preoperative localization of parathyroid adenomas and in directing surgical approach. Clin Endocrinol (Oxf) 65: 106-113. 